\title{
ONZE CIRCULATIE VAN GROVE ZILVEREN SPECIE EN DE BANKBILJETTEN VAN F I0.-
}

\author{
(Met een figuur).
}

Het bleek wenschelijk den omvang van de "actieve" circulatie van onze verschillende munten en de veranderingen, daarin in den loop van eenige achtereenvolgende jaren opgetreden, te leeren kennen. Hieruit toch zouden vermoedelijk besluiten zijn te trekken omtrent geleidelijke wijzigingen in de van elke muntsoort in de eerstkomende jaren benoodigde hoeveelheden, een vraagstuk van eenige praktische beteekenis.

Bij het uitwerken der gegevens, voor zoover die op de grove zilveren munten, rijksdaalders en guldens ${ }^{1}$ ) betrekking hadden ${ }^{2}$ ) kwamen eigenaardige regelmatigheden an het licht, die bij dezen of genen wellicht eenige belangstelling kunnen vinden. Voor hen mogen de uitkomsten van dit deel van het onderzoek hier in 't kort worden medegedeeld.

Voor het bovenomschreven doel waren de rijksdaalders in den asnvang nog niet van belang; van die muntsoort wordt jaarlijks een deel versmolten tot nieuwe guldens, halve guldens of pasmunt, zoowel voor Nederland als voor Indië. De voorrasd kan nog heel wat verminderen, voordat aan anvulling behoeft te worden gedacht, al schijnt de merkwaardig snelle toename van de voor de circulatie benoodigde hoeveelheid dezer speciesoort in Ned. Indië ${ }^{3}$ ) in den laatsten tijd in verband met de daarvoor wel geldende redenen de mogelijkheid niet uit te sluiten dat,

1) Zooals bekend is, spelen de halve guldens in ons land geen noomenswaarde rol.

2) Dat ik hierover kan beschikken, dank ik aan de groote en zeer gewaardeerde bereidwilligheid, waarmede de Directie der Nederlandsche Bank mij al het materiaal dat ik noodig had, verschafte.

3) In het verslag van den President van de Javasche Bank over 1906-1907 wordt hierop reeds (blz. 13) gewezen. 
tegen aller verwashting, nog in afzienbaren tijd zich de noodzaak van de bedoelde anvulling zal doen gevoelen. Toen zich echter bij het onderzoek der guldens-circulatie eigenaardige verschijnselen voordeden, achtte ik het wenschelijk om ook de rijksdaalders op gelijke wijze onderhanden te nemen. De voortdurende veranderingen in den omvang der circulatie dezer beide muntsoorten bleken toen grootendeels een analoog verloop te hebben.

Bij beide is hier onder "actieve" circulatie verstaan de hoeveelheid munt die op een bepaald oogenblik in het geheele land aanwezig wordt geacht, verminderd met den voorraad op dat oogenblik in kassen der Nederlandsche Bank (zonder de correspondentschappen) voorhanden.

Tot de totale in ons land op een bepaalden datum aanwezige hoeveelheid van elk der beide muntsoorten ben ik door schatting ${ }^{1}$ ) berustende op verschillende gegevens, gekomen. Met behulp van bekende wijzigingen in eenige voorafgaande jaren en ook nog na dien datum, zooals de nieuw-aangemunte en van of naar Indië verzonden hoeveelheden, kon door vooruit- en achteruitrekenen de totale omvang op verschillende tijdstippen worden afgeleid. In overeenstemming met de voorraden bij de Nederlandsche Bauk zijn al deze cijfers ${ }^{2}$ ) week voor week bepaald. Door

1) Stelt men het aantal hier en in Indië aanwezige guldens, 1 Januari 1907, op 100 millioen (aangemunt zijn 103.5 millioen) dan is er reden, hier niet nader toe te lichten, om deze te verdeelen in 25 millioen in Nederland en de rest in Indië.

De halve guldens (circa 58.5 mill. stukken) zijn volgens mijne gegevens te splitsen in een gedeelte van 3.5 millioen in Nederland en 55 millioen in Indië.

Neemt men verder aan (Muntverslag 1906, pag. 45) dat aan grof zilver in ons land $f 119.5$ millioen zou voorkomen en trekt men de aangegeven bedragen voor de guldens en halve guldens af, dan blijft een bedrag van omstreeks 93 millioen gulden aan rijksdaalders over, welk bedrag hier als in ons land op 1 Januari 1907 anwezig wordt beschouwd. Op dit cijfer voor de rijksdaalders en $f 25$ millioen voor de guldens op 1 Januari 1907 is de berekening der actieve circulatie op andere datums gebaseerd.

2) Deze zijn alle aangedaan met de fout, die aan de natuurlijk vrij onzekere schatting van de op den datum van uitgang totaal aanwezige bedragen kleefde. Maar veel doet dit tot het verdere niet af; het komt daarbij op de onderlinge verschillen aan en het verloop van de hoeveelheden; vrij zeker schuilen hierin geen andere onbekende oorzaken voor ennigszins belangrijke fouten. 
aftrek van laatstgenoemde voorraadcijfers werden de bedragen der actieve circulatie verkregen; uit elke vier of vijf voor ééne maand geldende is het gemiddelde genomen en dit als bedrag voor die maand beschouwd.

Đe verkregen cijfers voor de actieve circulatie van guldens en rijksdaalders, die hier wegens hun uitvoerigheid natuurlijk niet kunneu worden opgenomen, geven aanleiding tot verschillende opmerkingen. Bij elk der beide muntsoorten vestigt het verloop der bedragen, voor iederen Zaterdag bepaald, den indruk dat daarin zeer opmerkelijke regelmatigheden voorkomen. Gaat men het stijgen en dalen der bedragen van week tot week na, dan vindt men dat deze bij de guldens geheel gelijkmatig zòò op en neer gaan dat in elke maand één hoogte- en één laagtepunt valt; slechts tweemaal is bij de geleidelijke daling gedurende November en December een daarin nog te verwachten kleine verheffing onmerkbaar gebleven. Iets minder volmaakt maar toch even duidelijk doet hetzelfde verschijnsel zich bij de rijksdaalders voor; bij de jaarovergangen wordt het ook hier slechts enkele malen gestoord.

De nit de "week"cijfers berekende gemiddelde "maand"cijfers zijn overgebracht in grafische voorstellingen (zie de bijgevoegde diagrammen) die reeds bij den eersten blik doen zien dat hierin een duidelijke jaarlijksche periode voorkomt. Zoowel bij de guldens als bij de rijksdaalders is er elk jaar in den herfst een sterke stijging die eenigen tijd vóór en na 1 November haar hoogste waarde verkrijgt om dan snel te dalen. Dit maximum in het najaar klimt op zich zelve tamelijk geleidelijk ${ }^{1}$ )

1) De maximale "maand"cijfers voor de actieve circulatie zijn voor de rijksdaalders (in duizenden guldens)

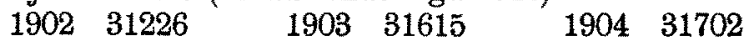

met stijgingen van 1.2 en $0.7 \mathrm{pCt}$. Voor de guldens

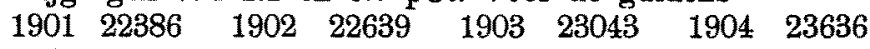

met stijgingen van $1.1,1.8$ en 2.6 pCt.

Ter vergelijking voeg ik hieraan de bevolkingscijfers van de laatste 10 jaren (in duizendtallen op 31 December) toe

$\begin{array}{llllllll}1896 & 4929 & 1899 & 5140 & 1902 & 5347 & 1904 & 5510 \\ 1897 & 5004 & 1900 & 5179 & 1903 & 5431 & 1905 & 5592 \\ 1898 & 5075 & 1901 & 5263 & & & & \end{array}$
met een gemiddelde jaarlijksche stijging van ongeveer $1.4 \mathrm{pCt}$.

De guldensbehoefte is in de laatste jaren met sneller tempo dan de bevolking geklommen; voor de rijksdaalders schijnt dit niet het geval te zijn, de gegevens behooren echter eerst talrijker te worden. 
jaar voor jaar, zoowel bij de.guldens als de rijksdaalders tot en met 1904, met uitzonderig slechts van de eenigzins hoogere Octoberwaarde der rijksdaalders in 1901. Heel eigenaardig echter is het dat van af 1905 het bedoelde maximum afwijkingen gaat vertoonen; bij de guldens daalt het in én jaar slechts weinig, om daarna weder zijn stijgeude beweging te herstellen; bij de rijksdaalders is de daling belangrijker, zoowel absoluut als relatief, en loopt zij bovendien over de twee volgende jaren, al zal vermoedelijk daarna ook de opgaande beweging weder den overhand verkrijgen.

Deze anomalie is van belang met het oog daarop dat juist bij een regelmatig verloop van de circulatie met eenig recht iets van de te verwachten behoefte kan worden voorspeld. Voordat eene verklaring van deze afwijking wordt gegeven, valt nog op enkele andere regelmatigheden in den omvang der actieve circulatie, in de figuren gemakkelijk waar te nemen, te wijzen.

Zoowel bij de guldens als de rijksdaalders vertoonen de grafische voorstellingen een sterke daling vanaf November tot ver in het volgende voorjaar en een sterke klimming vandaar tot October. Zonder één uitzondering komt in het laagste gedeelte der figuren nog eene andere, maar veel kleinere verheffing voor, zoodat aan weerszijden daarvan steeds van twee minima kan gesproken worden; de laatste vallen telkens samen met de maanden Maart eu Juni. April en Mei eischen dus steeds iets meer. Dat de 3-maanden-afstand Maart-Juni een rol speelt lijkt ook daarom waarschijnlijk, omdat deze kwartaalperiode nog meer te herkennen is. Immers de ordinaat voor September en December is zichtbaar iets korter dan de gemiddelden der voorafgaande en volgende maanden; in de figuren uit dit zich in een geringe inzinking voor September en December in het stijgende en dalende gedeelte, links en rechts van de hoofd-maxima.

Deze telken jare trouw terugkeerende verschijnselen zullen wellicht verklaard en toegelicht kunnen worden door hen, die meer van nabij met de dagelijksche behoefte aan grove zilveren specie en het geleidelijk verloop daarvan bekend zijn dan ondergeteekende; zij hebben in ieder geval het nut, dat zij vertrouwen geven in de relatieve deugdelijkheid dezer statistieken.

Over de bovenvermelde afwijking van de normale stijging 
der najaars-maxima sedert 1904 is darentegen wel een en ander in het midden te brengen. Al valt de oorzaak er van viet mathematisch te bewijzen, zoo kan men haar toch veilig zoekein in de ééne omstandigheid die op een normaal verloopend gebruik van grove specie in de laatste jaren in ons land invloed heeft gehad en wel in de vervanging van de circuleerende muntbiljetten van f 10 door baukbiljetten van dezelfde waarde, welke verwisseling, wat het tijdstip betreft, met het opgemerkte verschijnsel samenvalt. Zal dit ook verder de verklaring kunnen zijn dau moeten de nieuwe bankbiljetten dus in grootere hoeveelheden dan de vroegere muntbiljetten circuleeren; het meerdere bedrag toch zal een deel van het grove zilver overbodig gemaakt en uit de circulntie weggedrongen hebben. Om dit punt op te helderen loonde het, naar mijne meening, de moeite, na te gaan hoe de gang van zaken voor en wa den overgang van de f 10-munt- in -bankbiljetten op dit gedeelte van het terrein onzer ruilmiddeleu was geweest, teneinde ook $\mathrm{k}$ wantitatief den invloed van het kleive papier op den zilveromloop te kunnen vaststellen.

Het is bekend dat aan de f 10 -muntbiljetten, eerst als hulpmiddel gebruikt bij het herstel van ons muntwezen in de $50^{\text {er }}$ jaren door de wet van 26 April 1852 (Stbl. $\mathrm{n}^{\circ} 90$ ) een blijvende plaats werd ingeruimd en wel tot een bedag van $f 10$ millioen, later bij de wet van 27 April 1884. (Stbl. $n^{\circ} 98$ ) uitgebreid tot $f 15$ millioen. Deze hoeveelheden zouden ook gedeeltelijk uit biljetten vau f 50 kunnen bestaan, welke verhouding gelijdelijk gewijzigd is tot $\mathrm{f} 14$ millioen in $\frac{f}{2} 10$ - en $\mathrm{f} 1$ millioen in $\mathrm{f} 50$ muntbiljetten, in 1901. Maar ook daarna bleek dat aan de behoefte der circulatie aan het f 10-betaalmiddel nog geenzins was voldaan.

Dit kon verauderen nadat bij de lantste vernieuwing van het Octrooi van de Nederlandsche Bank (wet van 31 December 1903, Stbl. $\mathrm{n}^{0}$ 335) aan die instelling het recht werd toegekend bankbiljetten van $f 10$ in omloop te brengen, terwijl gelijktijdig (wet van 31 December 1903, Stbl. $n^{\circ} 336$ ) de muntbiljetten werden ingetrokken. De eigenlijke overgangsdatum was 1 October 1904. Toen daarna de omvang van deze papiersoort niet meer, als te voren, tot een bepaald bedrag beperkt was, bleek al ras de juistheid van de herhaaldelijk gemaakte opmerkingen over een gebleken grootere behoefte. Want belangrijk en snel is het 
circuleereud bedrag sedert de verwisseling toegenomen. Dit is als volgt berekend:

Uit de bekende intrekkingen der muntbiljetten na 1 October 1904 kan de totale circulatie op dien datum worden afgeleid. ${ }^{1}$ ) Verder waren de gegevens tot mijne beschikking ${ }^{2}$ ) omtrent de meerdere uitgifte dan terugname op bepaalde datums in de voorafgaande jaren en daaruit is gemakkelijk het circuleerend bedrag, maand voor maand, af te leiden, Er is geen aftrek gemaakt voor de hoeveelheden telkens in de kassen van de Nederlandsche Bank en vau betaalmeesters annwezig, omdat deze bedragen betekkelijk gering waren en zonder invloed op het geheel [zoo wisselden de f 10-muntbiljetten bij de Nederlaudsche Bank en hare agenten in den loop van 1904 slechts af van \pm 3 tot 6 tou].

Vauaf 1 October 1904 was er met beide soorten rekeuing te houden; de muntbiljetten-circulatie is eerst zeer snel en daarop verder geleidelijk afloopend gedaald. ${ }^{3}$ ) Met de bankbiljetten ging het natuurlijk in omgekeerden zin. Bij deze, waar de intrekking van het nieuwe papier in September 1905 een aquvang nam, zijn sedert de voortdurend weggenomen hoeveelheden in aftrek gebracht. De aldus bekende totaal-circulatie is telkens, week voor week, verminderd met wat bij de Nederlandsche Bank en hare kantoren aanwezig was. Als actief circuleerend op den eersten van elke maand is daarop het bedrag genomen dat voor den laatsten Zaterdag van de vorige maand was gevonden.

1) Er is verwaarloosd het betrekkelijk geringe bedrag dat ook nu nog niet ter verwisseling is aangeboden en dat wel voor een groot gedeelte verloren geraakt zal zijn. Bovendien zijn de intrekkingen der muntbiljetten beschouwd als te zijn geschied bij hun overdracht van de Nederlandsche Bank naar het Agentschap van het Ministerie van Financiën te Amsterdam. Eigenlijk hadden zij tellkens iets vroeger plaats. Deze tijdsverschuiving geeft een geringe anomalie in het stelsel mijner cijfers, die echter van ondergeschikten aard is.

2) Door de welwillendheid van den Agent van het Ministerie van Financiën te Amsterdam en den Referendaris bij dat Agentschap is mij het verkrijgen hiervan zeer vergemakkelijkt.

$\left.{ }^{3}\right)$ Hoe langzaam dit ten slotte verloopt blijkt hieruit dat van 1 Januari tot 1 November 1907 slechts f 8000 werd ingetrokken. 
Enkele cijfers mogen den overgang der f 10-biljetten nog toelichteu :

Op bovenaaugegeven wijze berekend bedroeg de circulatie der f 10 -muntbiljetten op

\begin{tabular}{|c|c|c|c|}
\hline Januári & 1901 & f 11.54 & millioen \\
\hline$"$ & 1902 & -12.64 & " \\
\hline " & 1903 & -13.29 & " \\
\hline 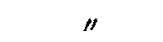 & 1904 & $=13.49$ & $"$ \\
\hline October & 1904 & -13.30 & 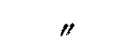 \\
\hline
\end{tabular}

met zeer langzame toename in de tusschenliggende perioden; een zeer weinig veranderend geheel derhalve. $\mathrm{Na} 1$ October 1904, zijn beide soorten nog naast elkaar in omloop:

\begin{tabular}{|c|c|c|c|c|}
\hline & & Muntbiljetten & Bankbiljetten & otaal \\
\hline Nove & 19 & f 10. & f 3.160 .000 & f 14.6 \\
\hline 1 Der & & 8.040 .000 & 5.06 & " \\
\hline & 1905 & 6.270 .000 & $" 7.550 .000$ & \\
\hline $\mathbf{F}$ & $"$ & " 4.990 .000 & "9.180.000 & 00 \\
\hline & $"$ & 3.950. & $" 10.3$ & \\
\hline $\begin{array}{lll}1 & A_{1}\end{array}$ & " & $" 3.0$ & $" 1$ & \\
\hline$M$ & $"$ & 2.4 & $" 1$ & \\
\hline $\mathrm{Ju}$ & " & 1.8 & $" 1$ & \\
\hline $\mathrm{Ju}$ & " & 1.5 & $" 1$ & $"$ \\
\hline stus & $" 1$ & $" 1.2$ & $\| 1$ & \\
\hline ber & : & $" 1.0$ & $\| 1$ & \\
\hline 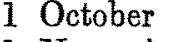 & $"$ & 0 & & \\
\hline November & " & 690. & $" 19.600$ & $" 1$ \\
\hline & 906 & $"$ & $\| 2$ & \\
\hline 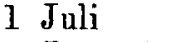 & & 170. & 112 & 000 \\
\hline 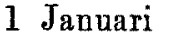 & 1907 & 80.000 & 112 & .000 \\
\hline & $"$ & $"$ & 112 & \\
\hline October & 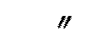 & 10.000 & 124. & 0.00 \\
\hline
\end{tabular}

Duidelijk springt de snelle toename in den omloop na October 1904 in het oog. Zooals reeds opgemerkt, valt hiermede een belangrijk verminderd gebruik van grof zilver, in het bijzonder rijksdaalders, samen. Gebrek aan f 10-papier had te voren tot meerder zilvergebruik aanleiding gegeven; na vrije uitgifte van het papier blijkt het, dat men zich zoo lang voor een deel met zilver had moeten behelpen, maar voor dat deel eigenlijk aan papier den voorkeur gaf, als het er slechts was geweest.

$\mathrm{Nu}$ is het ook niet bevreemdend meer dat de terugdringing 
bij de rijksdaalders en guldens niet zuiver gelijkvormige beelden gaf. Beide speciesoorten vervullen als grof zilver ten deele eenzelfde rol; als zoodanig zijn zij das na 1904 weer uit hun door toevallige omstandigheden vergroot terrein teruggezet. Maar de guldens hebben, als kleinere muntsoort, en dus ook onder omstandigheden in gebruik, waarin niet evengoed rijksdaalders waren te bezigen, nog een specifieke functie, die onafhankelijk is van de vorige. Deze moet hebben teweeggebracht dat de relatieve circulatievermindering bij de guldens geringer was en dat reeds na een jaar de stijgende beweging der guldens-circulatie opnieuw is begonnen.

Het blijft nog na te gaan in hoeverre er kwantitatief verband bestaat tusschen de plotselinge wijzigingen in de circulatie van het grove zilver en van de f 10-biljetten. Het is geenszins waar (al zou men dit wellicht vermoeden) dat de teruggedrongen hoeveelheid zilver ongeveer gelijk zou staan met het bedrag, waarmede de bankbiljetten dat der muntbiljetten vóór October 1904 overtreft; de vermindering der zilvercirculatie is anmerkelijk geringer. Immers, terwijl op 1 Januari $1904 \pm f 13.5$ millioen muntbiljetten in omloop was en tevoren maar zeer weinig minder, is later aan munt- en bankbiljetten te zamen, meer in gebruik (afgerond)

$$
\begin{array}{cccc}
\text { op } 1 \text { October } 1905 \text { f } 6.3 \text { millioen } \\
" 1 & \text { " } & 1906 ~ & 10.0 \text { " }
\end{array}
$$

De teruggang in de grove-zilver-circulatie is van geringeren omvang. Nemen wij de maximale bedragen (in October) die van rijksdaalders + guldens in omloop waren in de 3 laatste jaren, dan vinden wij daarvoor (afgerond)

October 1902 f 53.9 millioen

$$
\text { " } 1903 " 54.6 \text { " } 1904 " 55.3
$$

en zouden die bij gelijkmatige voortzetting hebben bedragen

October 1905 f 56.0 millioen

$$
\text { " } 1906 \text { " } 56.7 "
$$

terwijl zij op de laatstgenoemde tijdstippen waren respectievelijk 53.9 en 53.8 millioen dus 2.1 resp. 2.9 millioen minder. Vergelijkt men nu deze met de bovengevonden waarden dan blijkt de vermeerdering. der f 10 -biljetten verscheidene malen grooter te zijn geweest dan de terugdringing van het grove zilver. 
Nu lijkt het niet onwaarschijnlijk dat de meerdere omvang, dien het gebied van het 10-guldenspapier sedert 1904 verkreeg, ook zijne werking naar de andere zijde heeft doen gevoelen. Zeer stellige feiten zijn niet te noemen, maar eenig licht geven toch de volgende cijfers (ontleend aan de Verslagen van den President der Nederlandsche Bank) over het anntal bankbiljetten van $f 25$, dat op 31 Maart van de benedengenoemde jaren in circulatie was

$\begin{array}{llc} & & \text { Vermeerder } \\ 1899 & 1.276 .348 & 80.307 \\ 1900 & 1.356 .655 & 50.354 \\ 1901 & 1.407 .009 & 34.695 \\ 1902 & 1.441 .704 & 79.724 \\ 1903 & 1.521 .428 & - \\ 1904 & 1.512 .026{ }^{1} & - \\ 1905 & 1.562 .810 & - \\ 1906 & 1.578 .361 & 15.551 \\ 1907 & 1.600 .175 & 21.814\end{array}$

Vóór 1904 zijn de jaarlijksche verschilleu duidelijk grooter dan in de latere jaren; er zijn aanwijzingen voor eenige terugdringing in de geleidelijke uitbreiding dezer coupure aanwezig.

Met dat al wil het mij op grond van de aangevoerde cijfers voorkomen (het materiaal aan gegevens is te beperkt om verder te gaan) dat de grootere omvang der f 10-bankbiljetten zijne verklaring vindt niet alleen in het vervullen van functies die in de laatste jaren door een gedeelte van het grove zilver en door papier van $f 25$ waren verricht maar bovendien nog in een zelfstandige stijging der behoefte an dat betaalmiddel, eene stijging die relatief anmmerkelijk grooter is dan de bevolkingsaan was.

Utrecht, November 1907.

Horrsema.

1) Zon men tot de onderstelling niet gerechtigd zijn, dat de afwijking die dit cijfer vertoont verband houdt met de invoering der $f 10$-biljetten in hetzelfde jaar en de vertragingen die daarbij optraden? 


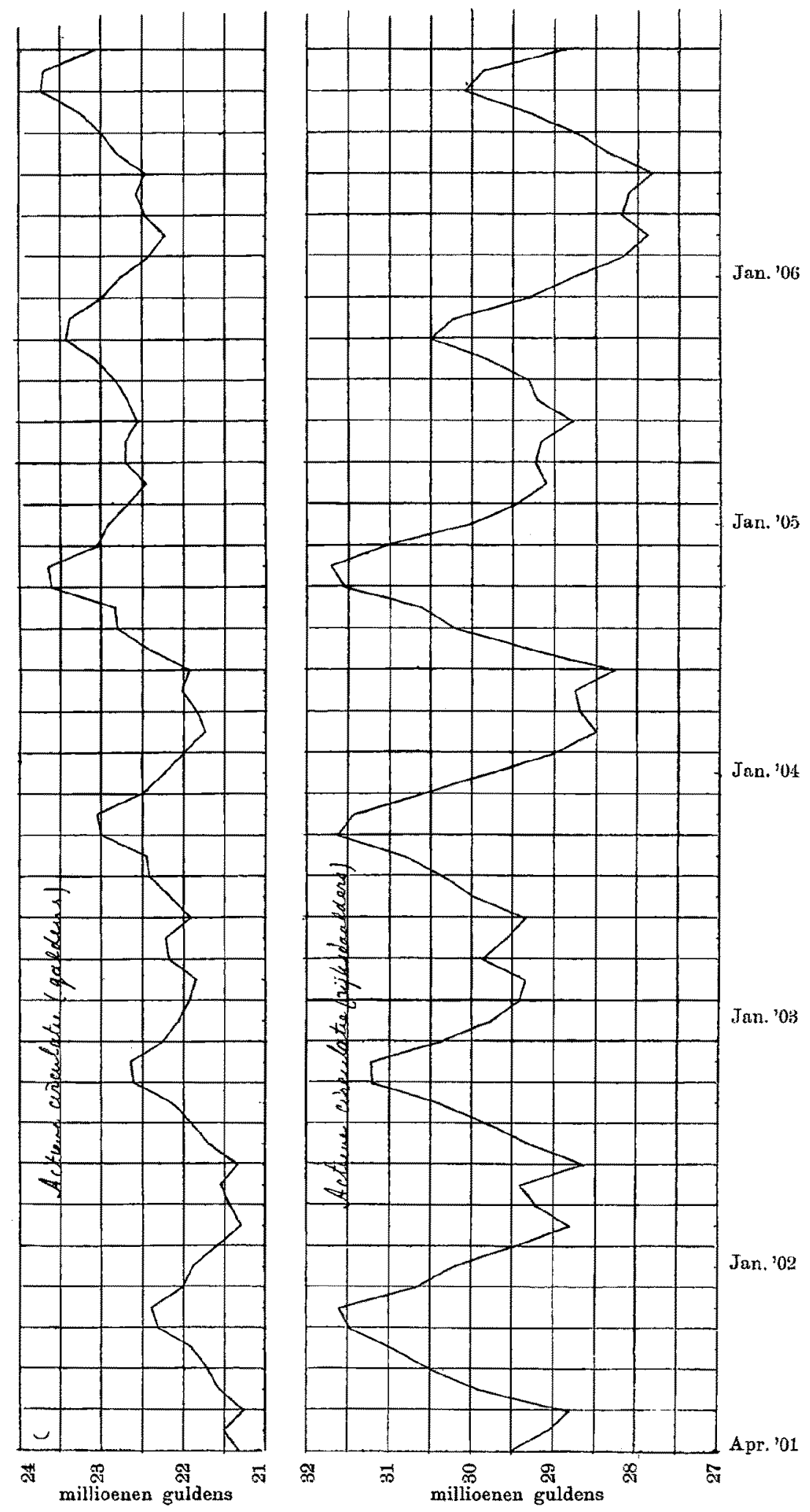

